\title{
Rafting and Elastoplastic Deformation of Superalloys Studied by Neutron Diffraction
}

\author{
James Coakley ${ }^{\mathrm{a}, \mathrm{b}, *}$, Eric A. Lass ${ }^{\mathrm{c}}$, Dong Mad ${ }^{\mathrm{d}}$, Matthew Frost ${ }^{\mathrm{e}}$, David N. Seidman ${ }^{\mathrm{a}}$, David C. Dunand ${ }^{\mathrm{a}}$, Howard J. \\ Stone $^{b}$ \\ ${ }^{a}$ Northwestern University, Department of Materials Science and Engineering, Evanston, IL 60208-3108, USA \\ ${ }^{b}$ Department of Materials Science and Metallurgy, University of Cambridge, Cambridge CB3 OFS, UK \\ ${ }^{c}$ Materials Science 8 Engineering Division, National Institute of Standards and Technology, Gaithersburg, MD 20899, USA \\ ${ }^{d}$ Oak Ridge National Laboratory, Chemical and Engineering Materials Division, Neutron Sciences Directorate, Oak Ridge, TN 37831, USA \\ ${ }^{e}$ Oak Ridge National Laboratory, Instrument and Source Division, Oak Ridge, TN 37831, USA
}

\begin{abstract}
The rafting of monocrystalline Ni- and Co-based superalloys has been studied by neutron diffractometry. Lattice parameter misfit values and the difference in phase stiffnesses at room temperature, $650{ }^{\circ} \mathrm{C}$, and $900{ }^{\circ} \mathrm{C}$ are presented. These microstructural parameters should assist in refining computer models that aim to predict precipitate evolution in superalloys and aid future alloy design. The nature of rafting is shown experimentally to be dependent upon the lattice parameter misfit. The $900{ }^{\circ} \mathrm{C}$ yield strength of the $\gamma$-phase of the Co-based superalloy with a rafted microstructure occurs at $\sim 100 \mathrm{MPa}$, when loaded at a low strain rate.
\end{abstract}

Key words: neutron diffraction, superalloy, rafting, yield phenomena, elastic behaviour

Ni-based and the latest Co-based superalloys are strengthened by ordered $\mathrm{L}_{2} \gamma^{\prime}$-precipitates which are embedded coherently within a disordered fcc $\gamma$-matrix. Neutron diffractometry has been applied extensively to the study of polycrystalline [1-6] and monocrystalline [7] Ni-based superalloys to characterise the constrained (or effective) phase elastic constants, $E^{\gamma^{\prime}, \text { eff }}$ and $E^{\gamma, \text { eff }}$, and constrained lattice parameter misfit values

$$
\delta^{\mathrm{eff}}=\frac{2\left(d^{\gamma^{\prime}, \mathrm{eff}}-d^{\gamma, \mathrm{eff}}\right)}{d^{\gamma^{\prime}, \mathrm{eff}}+d^{\gamma, \mathrm{eff}}}
$$

where $d^{\gamma^{\prime} \text {,eff }}$ and $d^{\gamma, \text { eff }}$ are the constrained, measured $d$ spacing values at the temperatures and stresses of interest. Evaluation of the constrained phase elastic constants gives confidence in more advanced neutron diffraction studies of Ni-based superalloys, such as intergranular and interphase load partitioning [1-3, 5-7], deduction of slip modes [4], and lattice strain evolution during creep regimes [18]. Similarly, in-situ X-ray diffraction at synchrotron facilities has been utilised to gain insight into alloy behaviour including: the effect of alloying on lattice parameter misfit [8]; the kinetics of phase transformations [9]; the temperature dependence of lattice parameter misfit [10-13]; and, the effect of applied stress at elevated temperatures [14-17]. However, to date, the study of Co-based superalloys by neutron diffraction has been limited. The variation of lattice parameter misfit with temperature has been deduced

\footnotetext{
*Corresponding Author. James Coakley. Tel: +1 312774 8634; fax: +1 847467 2269; E-mail address: james.coakley@northwestern.edu
}

Preprint submitted to Scripta Mater in polycrystalline ternary and quaternary alloys [19-23], and constrained phase elastic constants have been measured at room temperature and $650^{\circ} \mathrm{C}[21]$.

The deduction of phase elastic constants and lattice parameter misfit values by neutron diffraction are of fundamental interest, as the strengthening $\gamma^{\prime}$-precipitate size and morphological evolution at elevated temperatures (with or without applied stresses) are dependent on these microstructural parameters [24]. The direction and rate of rafting (directional coarsening at elevated temperature and stress) are dependent on the direction and magnitude of the applied load, the lattice parameter misfit value, and the fractional difference in constrained elastic constants of $\gamma^{\prime}\left(E^{\gamma^{\prime}, \mathrm{eff}}\right)$ and $\gamma\left(E^{\gamma, \mathrm{eff}}\right)[24]$

$$
m^{\mathrm{eff}}=\frac{2\left(E^{\gamma^{\prime}, \mathrm{eff}}-E^{\gamma, \mathrm{eff}}\right)}{E^{\gamma^{\prime}, \mathrm{eff}}+E^{\gamma, \mathrm{eff}}}
$$

The influence of dislocations on precipitate rafting must also be considered during creep. Specifically, it is known that raft orientation and particle growth rate are dependent upon the relief of lattice parameter misfit strains in specific channels by dislocations at the $\gamma / \gamma^{\prime}$ interface $[25,26]$.

This paper studies the lattice strain response of both $\gamma$ - and $\gamma^{\prime}$-phases during loading of monocrystalline $\mathrm{Ni}$ and Co-based superalloys with cuboidal and rafted $\gamma^{\prime}$ microstructures at room temperature, $650{ }^{\circ} \mathrm{C}$ and $900{ }^{\circ} \mathrm{C}$. $\delta^{\text {eff }}$ values of the Ni-based superalloy, with rafted microstructures, are found to be highly anisotropic, while those of the Co-based superalloy values are isotropic. Rafting is shown to be dependent on the lattice parameter misfit sign and magnitude, in agreement with theory [27]. Load parti-

March 8, 2017 

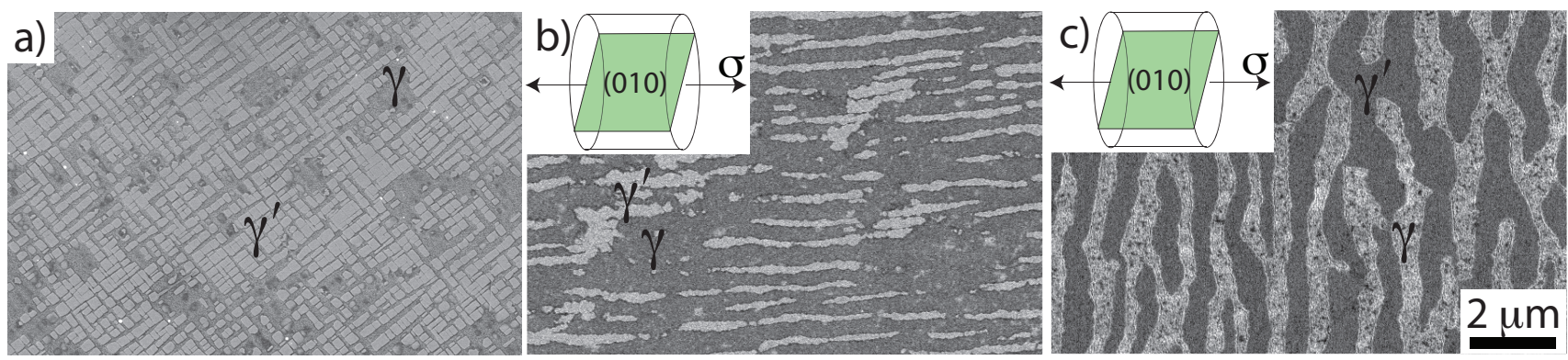

Figure 1: Representative secondary emission SEM images of etched cross-sections showing a) the cuboidal $\gamma^{\prime}$ microstructure and b) the rafted $\gamma^{\prime}$-microstructure of the single crystal Co-based superalloy (L19C); and c) the rafted $\gamma^{\prime}$-microstructure of the single crystal Ni-based superalloy (CMSX-4). Insets: The loading direction is shown relative to the precipitate orientation. The $\gamma$-phase was etched with an aqueous solution of 2.5 vol.\% phosphoric acid at $2.5 \mathrm{Vdc}$ for $\sim 1 \mathrm{~s}$.

tioning from $\gamma$ to $\gamma^{\prime}$ occured on yielding of the Co-based superalloy with rafted $\gamma^{\prime}$-microstructures. The quantification of the constrained lattice parameter misfit values and elastic constants from room temperature to elevated temperatures will facilitate models of the precipitate evolution in Co-based superalloys, as has been attempted for the Ni-based superalloys, e.g. [28].

(100) oriented single crystal bars of the Ni-based superalloy CMSX-4 were provided by Rolls-Royce plc. ${ }^{1}$, Derby, U.K., following a proprietary solution heat-treatment and a two-step aging process of $1140{ }^{\circ} \mathrm{C} / 2 \mathrm{~h}+870{ }^{\circ} \mathrm{C} / 16 \mathrm{~h}$. (100) oriented bars of single crystal Co-based superalloy with the composition Co-27.3Ni-2.7Al-1.4Ti-5.8W-4.2Mo-2.8Nb-2.8Ta wt.\% (Co-28.8Ni-6.2Al-1.8Ti-2.0W-2.7Mo-1.8Nb-0.9Ta at.\%), determined by inductively coupled plasma optical emission spectrometry and labeled L19C, were cast by AlcoaHowmet Research Center and Exothermics Inc., New Jersey, U.S.A.; with a final heat-treatment of $1300^{\circ} \mathrm{C} / 24 \mathrm{~h}+$ $900^{\circ} \mathrm{C} / 24 \mathrm{~h}$. The microstructure following this heat-treatment is shown in Figure 1a.

$12.7 \mathrm{~mm}$ gauge diameter Ni-based superalloy single crystal and $6.35 \mathrm{~mm}$ gauge diameter Co-based single crystal superalloy cylindrical tensile specimens were machined from the heat-treated bars, with $40 \mathrm{~mm}$ gauge lengths. Samples of the Co-based superalloy were crept under tension at $900^{\circ} \mathrm{C} / 100 \mathrm{MPa}$ for $20 \mathrm{~h}$ with $0.2 \%$ strain accumulation, producing P-type $\gamma^{\prime}$-rafts (aligned parallel to the tensile loading direction), Figure 1b. Samples of the Ni-based superalloy were crept under tension at $1150^{\circ} \mathrm{C} / 100 \mathrm{MPa}$ for $10 \mathrm{~h}$ with $0.7 \%$ strain accumulation, producing N-type $\gamma^{\prime}$-rafts (aligned normal to the tensile loading direction), Figure 1c. The samples were heated by an induction coil with the sample grips chilled. Displacement was recorded with a $12 \mathrm{~mm}$ high-temperature extensometer centred on the gauge length. The temperature gradient across the extensometer length was always within $10^{\circ} \mathrm{C}$ of the target temperature, and thus can be considered isothermal.

In order to study the lattice strain response of each

\footnotetext{
${ }^{1}$ Any mention of commercial companies or products herein is for information only; it does not imply recommendation or endorsement by NIST.
}

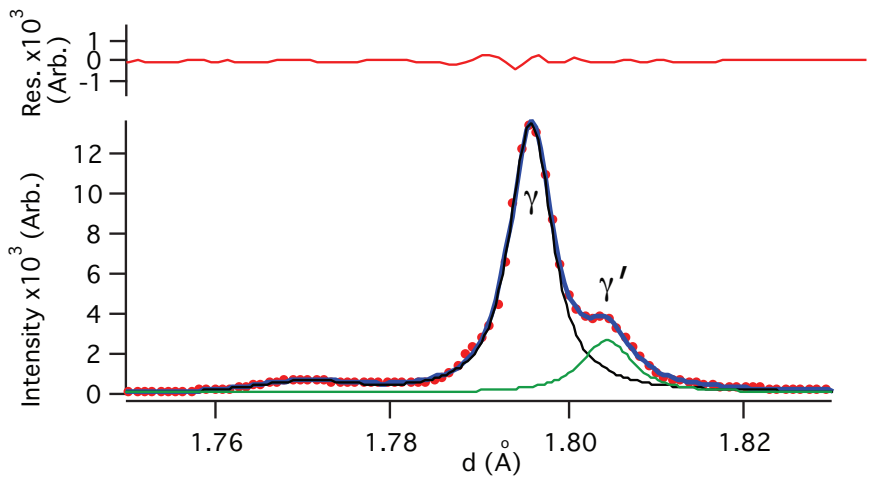

Figure 2: Room temperature, $50 \mathrm{MPa}$, Co-based superalloy diffraction data with rafted $\gamma^{\prime}$-microstructure showing the (200) $\gamma+\gamma^{\prime}$ composite peak and a pseudo-Voigt doublet peak fit to the data, along with the residual (res) error of the fit to the data.

phase in the linear elastic loading regime, in-situ neutron diffraction measurements were performed by sequentially stepping the applied tensile stress after each measurement at room temperature, $650{ }^{\circ} \mathrm{C}$ and $900{ }^{\circ} \mathrm{C}$ with samples of: (i) a Co-based superalloy with cuboidal $\gamma^{\prime}$-microstructure (Figure 1a); (ii) a Co-based superalloy with P-type $\gamma^{\prime}$ rafts (Figure 1b); (iii) a Ni-based superalloy with N-type $\gamma^{\prime}$-rafts (Figure 1c). All $900^{\circ} \mathrm{C}$ measurements were taken between $15-150 \mathrm{MPa}$. The room temperature and $650^{\circ} \mathrm{C}$ measurements of the rafted $\gamma^{\prime}$ Co-based superalloy were taken between $15-300 \mathrm{MPa}$, while those of the cuboidal $\gamma^{\prime}$ Co-based superalloy and rafted $\gamma^{\prime}$ Ni-based superalloy were taken between $15-550 \mathrm{MPa}$. These stress ranges were selected to try to ensure that the alloy under test remained in the elastic regime during testing. Each ramp in stress between diffraction measurements was linear with time and occurred over a 1 min time period.

Neutron diffraction measurements were performed on VULCAN [29], the time-of-flight (TOF) engineering neutron diffractometer at the spallation neutron source (SNS), Oak Ridge National Laboratory (ORNL), Tennessee, U.S.A., in a similar manner to described previously [7]. The incident beam, sample and detector banks were positioned to give the longitudinal lattice plane displacement in one 


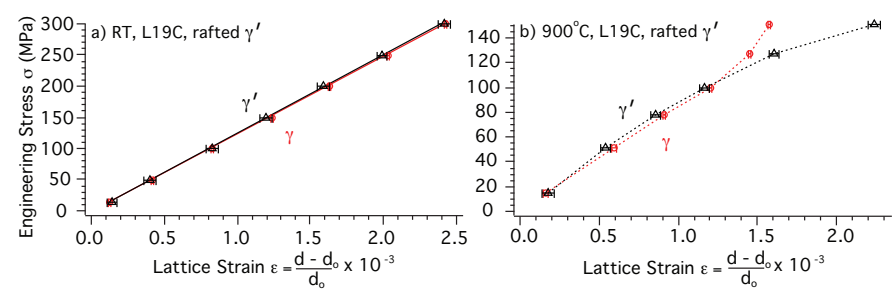

Figure 3: Measured engineering stresses and constrained lattice strains obtained in the longitudinal direction from the $\gamma$ (red) and $\gamma^{\prime}$ (black) phases within a Co-based superalloy during loading of the samples by time-of-flight diffraction at: a) and b) room temperature (RT) and $900^{\circ} \mathrm{C}$, respectively, with rafted $\gamma^{\prime}$ microstructure. Linear fits to the data are shown in a).

detector and the transverse lattice plane displacement in the other. The beam frequency was $60 \mathrm{~Hz}$ in the high resolution mode with count times of $20 \mathrm{~min}$ for each diffraction measurement performed and a $7 \mathrm{~mm}$ irradiated gauge volume was centred at the middle of the specimen and extensometer.

Pseudo-Voigt peak functions were fitted to the diffraction spectra peaks by an iterative least-squares error minimisation procedure, in a similar manner to [1, 7]. For the case of the Co-based superalloys, the intensities of the $\{300\} \gamma^{\prime}$ peaks were too weak to determine accurately the $\gamma^{\prime}$ d-spacing, but were sufficient to identify the $\gamma^{\prime}$ peakposition in the $\{200\} \gamma+\gamma^{\prime}$ doublet peak, by $d_{\{200\}}^{\gamma^{\prime} \text {,eff }}=$ $1.5 d_{\{300\}}^{\gamma^{\prime}, \text { eff }}$. The Co-based superalloy $\{200\} \gamma+\gamma^{\prime}$ peaks were widely separated (indicating a large lattice parameter misfit value) and fitted with a pseudo-Voigt doublet peak. For consistent fitting it was necessary to fix the Voigt peak widths and shapes as being constant at each temperature, which is reasonable due to limited to no plastic deformation occurring during the measurements. For the Ni-based superalloy, the $\{200\} \gamma+\gamma^{\prime}$ peak-positions were overlapping (indicating a smaller lattice parameter misfit value), and this required the $\{200\} \gamma^{\prime}$ peak positions to be constrained at $d_{\{200\}}^{\gamma^{\prime}, \text { eff }}=1.5 d_{\{300\}}^{\gamma^{\prime}, \text { eff }}[1,7]$. A peak fit to the diffraction data from the Co-based superalloy with rafted $\gamma^{\prime}$-microstructure is shown in Figure 2.

Linear elastic lattice strain responses without yielding were exhibited for each in-situ neutron diffraction loading experiment at room temperature (Figure $3 \mathrm{a}$ ), $650^{\circ} \mathrm{C}$ and $900^{\circ} \mathrm{C}$, with the exception of the Co-based superalloy with a rafted $\gamma^{\prime}$-microstructure at $900{ }^{\circ} \mathrm{C}$, which yielded (Figure 3b). In Figure $3 \mathrm{~b}$ there is an initial linear regime to $\sim$ $100 \mathrm{MPa}$, above which the $\gamma$ phase yields and additional elastic strain is transferred to the strengthening $\gamma^{\prime}$ phase.

The constrained elastic moduli and effective misfits are presented in Table 1, along with the alloy elastic modulus determined from the strain gauge $(E)$. Following the peak fitting of the diffraction data at each temperature, the $\{200\} d$-spacing value of each phase was plotted against the engineering stress, and the $d_{0}$ value at zero stress was found from the y-axis intercept of a linear fit to the data. The constrained lattice parameter misfit values at zero stress were then calculated (using Eqn. 1) along the longitudinal direction, parallel to the loading axis, labelled $\delta_{(h 00)}^{\text {eff }}$, and transverse to the loading axis, labelled $\delta_{(0 k 0)}^{\text {eff }}$ (see Figure $1 \mathrm{~b}$ and c for reference). The constrained lattice strains for each phase at each stress were calculated as $\varepsilon=\left(d-d_{0}\right) / d_{0}$ and plotted as stress-lattice strain graphs, with the slope of the linear fits corresponding to the constrained phase lattice stiffnesses, Figure 3. In Table $1, E_{(h 00)}^{\mathrm{eff}}$ is the constrained stiffness of each phase in the longitudinal direction and $E_{(0 k 0)}^{\mathrm{eff}}$ is that in the transverse direction. The $m$ parameter was calculated from these stiffness data using Eqn. 2. The transverse data were sufficiently reliable to allow the $d_{0}$ value to be determined in the transverse direction and thereby calculate the lattice parameter misfit. However, the error in the fit of the transverse elastic moduli was sufficiently large that it is misleading to compare Poisson's ratio values of each phase at each temperature, other than noting that they were in a range of $0.29-0.57$. Difficulties with the transverse diffraction data analysis are common, and are frequently not presented, for example [1].

The Co-based superalloy possesses similar positive constrained lattice parameter misfits in the (100) and (010), lying between $0.45-0.68 \%$ for all measurements. This produces $\mathrm{P}$-type rafts aligned along the tensile axis at $940^{\circ} \mathrm{C} / 100 \mathrm{MPa}$ in this alloy, which have been noted before experimentally (e.g. [30, 31]) and predicted [24]. Work on a ternary alloy, Co-9Al-9W at.\%, has shown that the constrained lattice parameter misfit value is approximately constant $\left(\delta^{\text {eff }} \sim 0.72 \%\right.$ ) from room temperature to $600{ }^{\circ} \mathrm{C}$, but then steadily decreases to $\delta^{\text {eff }} \sim 0.1 \%$ at $900^{\circ} \mathrm{C}[19]$. A similar trend was noted by Yan et al. [21] for Co-6.5Al$6 \mathrm{~W}-2 \mathrm{Ti}$ at. $\%$, which had a stable $\delta^{\text {eff }} \sim 0.6 \%$ to $700{ }^{\circ} \mathrm{C}$, after which it decreased to $\sim 0.5 \%$ at $800^{\circ} \mathrm{C}$. Both authors attributed the decrease of lattice parameter misfit to the onset of dissolution of the $\gamma^{\prime}$-phase. However Yan et al. [21] also observed that Co-10Al-5W-2Ta at.\% possessed a stable $\delta^{\text {eff }} \sim 0.7$ to $800{ }^{\circ} \mathrm{C}$. Similarly, Tanaka et al. [32] identified a progressively decreasing $\delta^{\text {eff }}$ value from room temperature $\left(\delta^{\mathrm{eff}} \sim 0.7 \%\right)$ to $800{ }^{\circ} \mathrm{C}\left(\delta^{\mathrm{eff}} \sim 0.52 \%\right)$ for Co-20Ni-9Al-7W-2Ta at. \%. The alloy studied in this work, L19C, is highly alloyed, but notably also possesses 1 at. $\%$ Ta and possesses a stable $\delta^{\text {eff }} \sim 0.5$ to $900{ }^{\circ} \mathrm{C}$. Thus, it appears that $\delta^{\text {eff }}$ can be tailored and stabilised, particularly through Ta additions.

The positive $\delta_{(h 00)}^{\text {eff }}$ values and negative $\delta_{(0 k 0)}^{\text {eff }}$ values of the Ni-based superalloy with rafted $\gamma^{\prime}$-microstructure are highly anisotropic. A load transfer from $\gamma$ to $\gamma^{\prime}$ during the rafting treatment should be observed as a positive misfit in the longitudinal direction, and a negative misfit in the transverse direction. The Ni-based superalloy accumulated $0.7 \%$ plastic strain during the rafting treatment, while there was limited change in the Co-based superalloy misfit values, as this alloy only accumulated $0.2 \%$ plastic strain during rafting. 
Table 1: Elastic modulus $(E)$ of the Ni-based superalloy, CMSX-4, and Co-based superalloy, L19C, constrained elastic moduli of each phase in the longitudinal direction $\left(E_{(h 00)}^{\text {eff }}\right)$ and $m$ parameter, and constrained lattice parameter misfit in the longitudinal $\left(\delta_{(h 00)}^{\text {eff }}\right)$ and transverse $\left(\delta_{(0 k 0)}^{\text {eff }}\right)$ directions at each temperature with cuboidal or rafted $\gamma^{\prime}$-microstructures.

\begin{tabular}{|c|c|c|c|c|c|c|c|}
\hline Alloy & $\begin{array}{l}\mathrm{T} \\
{ }^{\circ} \mathrm{C}\end{array}$ & $\begin{array}{c}E \\
\mathrm{GPa}\end{array}$ & $\begin{array}{c}E_{(h 00)}^{\gamma^{\prime}, \text { eff }} \\
\mathrm{GPa}\end{array}$ & $\begin{array}{c}E_{(h 00)}^{\gamma^{, \text {eff }}} \\
\text { GPa }\end{array}$ & $m_{(h 00)}^{\mathrm{eff}}$ & $\begin{array}{c}\delta_{(h 00)}^{\mathrm{eff}} \\
\%\end{array}$ & $\begin{array}{c}\delta_{(0 k 0)}^{\mathrm{eff}} \\
\%\end{array}$ \\
\hline CMSX-4 $[7,18]$ & RT & - & $128 \pm 3$ & $109 \pm 7$ & 0.16 & -0.06 & - \\
\hline CMSX-4 [18] & 650 & - & $105 \pm 4$ & $106 \pm 7$ & -0.01 & -0.23 & - \\
\hline CMSX-4 $[7,18]$ & 900 & - & $87 \pm 2$ & $89 \pm 3$ & -0.02 & -0.22 & - \\
\hline CMSX-4 Raft & $\mathrm{RT}$ & $133 \pm 1$ & $133 \pm 3$ & $125 \pm 3$ & 0.06 & 0.33 & -0.27 \\
\hline CMSX-4 Raft & 650 & $108 \pm 2$ & $107 \pm 1$ & $107 \pm 2$ & 0 & 0.28 & -0.28 \\
\hline CMSX-4 Raft & 900 & $97 \pm 8$ & $103 \pm 4$ & $94 \pm 4$ & 0.09 & 0.04 & -0.33 \\
\hline L19C Cube & RT & $140 \pm 1$ & $139 \pm 3$ & $130 \pm 2$ & 0.07 & 0.55 & 0.53 \\
\hline L19C Cube & 650 & $115 \pm 2$ & $108 \pm 1$ & $101 \pm 2$ & 0.07 & 0.52 & 0.51 \\
\hline L19C Cube & 900 & $88 \pm 7$ & $105 \pm 9$ & $65 \pm 3$ & 0.47 & 0.52 & 0.45 \\
\hline L19C Raft & RT & $122 \pm 3$ & $126 \pm 1$ & $124 \pm 1$ & 0.02 & 0.48 & 0.62 \\
\hline L19C Raft & 650 & $107 \pm 2$ & $109 \pm 2$ & $110 \pm 2$ & -0.01 & 0.48 & 0.68 \\
\hline L19C Raft & 900 & $57 \pm 4$ & $86 \pm 5$ & $81 \pm 1$ & 0.06 & 0.46 & 0.48 \\
\hline
\end{tabular}

According to the classic model of Pineau [24, 33], rafting can only occur if the $\gamma^{\prime}$-phase is stiffer than the $\gamma$ matrix, i.e. $m>0$. Experimental quantification of $m$ at elevated temperatures is limited, and is typically estimated to be 0.1 for the Ni-based superalloys [24]. In this work, it is interesting to note that $m_{(h 00)}^{\mathrm{eff}} \sim 0$ at $650{ }^{\circ} \mathrm{C}$ for the Ni-based superalloy with cuboidal [18] and rafted $\gamma^{\prime}$ microstructures, and rafting does not occur at this temperature [18], but does occur at $900^{\circ} \mathrm{C}[18]$ where $m_{(h 00)}^{\text {eff }} \sim$ 0.1 . However, this theory neglects the role of dislocations, and the observation of $\gamma^{\prime}$ rafts formed at $900^{\circ} \mathrm{C}$ may simply be related to the higher diffusion rates at elevated temperatures.

It is unclear if rafting would occur at $650{ }^{\circ} \mathrm{C}$ for the Co-based superalloy in the absence of plastic strain, as $m_{(h 00)}^{\text {eff }} \sim 0.07$ for the cuboidal $\gamma^{\prime}$-structure and $m_{(h 00)}^{\text {eff }} \sim$ 0 for the rafted structure. For the Co-based superalloy with a cuboidal $\gamma^{\prime}$-microstructure at $900{ }^{\circ} \mathrm{C}, m_{(h 00)}^{\mathrm{eff}} \sim 0.5$. Given the large magnitude of this parameter, the peak fitting constraints were altered to check for a procedural error, but the $m_{(h 00)}^{\text {eff }}$ value was always within $0.35-0.5$. In this case, the model of Pineau predicts that rafting will occur on loading, even in the absence of plastic deformation [33].

The alloy elastic modulus should lie within or close to the range of the elastic moduli of $\gamma$ and $\gamma^{\prime}$. This was observed for all measurements except the rafted $\gamma^{\prime}$ Co-based superalloy measurements at $900^{\circ} \mathrm{C}$. In this case, the alloy elastic modulus was notably low, being $\sim 60 \mathrm{GPa}$. It is possible that this arose as a result of fitting to the limited number of data points in the elastic regime at this temperature. The constrained elastic modulus $E_{(h 00)}^{\gamma^{\text {eff }}} \sim 65 \mathrm{GPa}$ of the $\gamma$-phase of the Co-based superalloy with embedded cuboidal $\gamma^{\prime}$ is also low. The microstructure changes rapidly at this temperature and stress (it is close to the known rafting condition of $940^{\circ} \mathrm{C} / 100 \mathrm{MPa}$ ). Whilst it is plausible that this experimental issue affects the determined constrained elastic moduli, it is noted that the alloy elastic modulus lies halfway between the bounds of the $\gamma$ and $\gamma^{\prime}$ constrained elastic moduli, and the volume fraction of the unrafted alloy is $\sim 50 \%$. This suggests that this may indeed be indicative of a significantly lower elastic modulus in the $\gamma$-phase at this temperature.

It is clear that at $900{ }^{\circ} \mathrm{C}$ the $\gamma$-phase in the Co-based superalloy is weak, yielding at only $100 \mathrm{MPa}$ when loaded at a low strain rate and the precipitates are rafted, Figure $3 \mathrm{~b}$. For this test, the strain rate was $\sim 10^{-5} \mathrm{~s}^{-1}$ prior to yielding at $100 \mathrm{MPa}$. The low strain rate is noted as superalloys can exhibit a dependency of yield stress with strain rate at elevated temperatures, for example [35]. This low yield stress is a concern for alloy design as plastic deformation of this phase will limit the temperatures and stresses that may be tolerated in service. In comparison, the yield strength in CMSX-4 at $900^{\circ} \mathrm{C}$ has been reported to be $\sim 875 \mathrm{MPa}[34]$ and no evidence of $\gamma$ phase yielding was observed during the experiment up to an applied tensile stress of $150 \mathrm{MPa}$. Thus, it appears that if the Co-based superalloys are to supersede the Ni-based superalloys in gas-turbine applications, the high temperature phase strength must be increased, along with high temperature phase stability.

In summary, the rafting of both $\mathrm{Ni}$ - and Co-based superalloys has been studied by neutron diffractometry. The nature of rafting was conclusively shown to be dependent upon both the direction and magnitude of the constrained lattice parameter misfit values, as suggested previously [27]. The $m$ parameter values have also been quantified, which are of particular relevance to directional coatsening theories in the absence of plastic deformation [24]. Yielding at $900^{\circ} \mathrm{C}$ of the $\gamma$-phase of the Co-based superalloy with a rafted microstructure was observed at $\sim 100 \mathrm{MPa}$. This strength must be improved with judicious alloying if Co-based superalloys are to supersede $\mathrm{Ni}$-based superalloys in load bearing applications at high temperatures. The data presented will help refine computer-based models that aim to predict precipitate evolution in superalloys.

\section{Acknowledgements}

The contributions of: Stephen DiPietro at Exothermics Inc., New Hampshire; John Koppes at Alcoa-Howmet Research Center, Missouri; and Neil Jones of Rolls-Royce plc., Derby, UK. This work was performed under awards 70NANB14H012 from U.S. Department of Commerce, National Institute of Standards and Technology as part of the Center for Hierarchical Materials Design (ChiMad), and the European Union Seventh Framework Programme under the Marie Curie grant agreement No. 628643. The neutron scattering study at ORNLs Spallation Neutron Source was sponsored by the Scientific User Facilities Division, Office of Basic Energy Sciences, US Department of Energy. This work made use of the EPIC facility of the NUANCE Center at Northwestern University, supported by SHyNE Resource (NSF NNCI-1542205); the MRSEC program (NSF DMR-1121262) at the Materials Research Center; the Keck Foundation; and the State of Illinois, through the IIN. 


\section{References}

[1] Stone HJ, Holden TM, Reed RC. Acta Mater 1999;47(17):4435

2 Coakley J \& Dye D. Scripta Mater 2012;67:435

[3. Preuss M, daFonseca JQ, Grant B, Knoche E, Moat R, Daymond MR. Superalloys 2008: 11th International Symposium on Superalloys, TMS 2008;405

[4] Daymond MR, Preuss M, Clausen B. Acta Mater 2007;55:3089

5. Ma S, Brown D, Bourke MAM, Daymond MR, Majumdar BS. Mater Sci Eng A 2007;339:141

[6] Ma S, Rangaswamy P, Majumdar BS. Scripta Mater 2003; 48:525

[7] Dye D, Coakley J, Vorontsov VA, Stone HJ, Rogge RB. Scr Mater 2009;61:109

[8] Bruno G, Schonfield B, Kostorz G. Z Metallkd ;94:12

[9] Collins DM, Crudden DJ, Alabort E, Connolley T, Reed RC. Acta Mater 2015;94:244

[10] Pinto HC, Bruno G. J Synchrotron Rad 2003;10:148

11. Bruno G, Schumacher G, Pinto Cavalcanti H. Metall Mater Trans A;34:193

[12] Bruno G, Pinto Cavalcanti H. Superalloys 2004: 10th International Symposium on Superalloys, TMS 2004;837

[13] Diologent F, Caron P, d'Almeida T, Chambreland S, Jacques A, Bastie P. International Journal of Materials Reseach 2006; 97(8):1136

[14] Le Graverend JB, Dirand L, Jacques A, Cormier J. Metall Mater Trans A;43(11):3946

[15] le Graverend JB, Jacques A, Cormier J, Ferry O. Acta Mater 2015;84:65

[16] Dirand L, Jacques A, Chateau-Cornu J Ph,Schenk T, Ferry O, Bastie P Phil Mag 2013;93(10):1384

[17] Dirand L, Cormier J, Jacques A, Chateau-Cornu J Ph,Schenk T, Ferry O, Bastie P Mater Char 2013;77:32

[18] Coakley J, Reed RC, Warwick JLW, Rahman KM, Dye D. Acta Mater 2012;60:2729

[19] Pyczak F et al. J Alloys \& Compd 2012;632:110

[20] Yan HY, Vorontsov VA, Coakley J, Jones NG, Stone HJ, Dye D. Superalloys 2012: 12th International Symposium on Superalloys, TMS 2012;705

[21] Yan HY, Coakley J, Vorontsov VA, Jones NG, Stone HJ, Dye D. Mater Sci \& Eng A 2014;613:201

[22] Zenk, CH, Neumeier S, Stone HJ, Göken M. Intermetallics 2014; $55: 28$

[23] Zenk, CH, Bauer A, Goik P, Neumeier S, Stone HJ, Göken M. Metall Mater Trans A 2016;47(5):2141

[24] Nabarro FRN. Metall Mater Trans A 1996;27:513

25] Matan N, Cox DC, Rae CMF, Reed RC. Acta Mater 1999; 47(7):2031

[26] Pollock TM \& Argon AS. Acta Metall Mater 1993;42(6):1859

27. Mughrabi H Acta Mater 2014;81:21

28 Li SY, Wu WP, Chen MX. Acta Mech Sin 2016;32(1):135

29] An K, Skorpenske HD, Stoica AD, Ma D, Wang XL, Cakmak E. Metall Mater Trans A 2011;42 (1):95

[30] Liu Q, Coakley J, Seidman DN, Dunand DC. Metall Mater Trans A 2016;47:6090

[31] Titus MS, Suzuki A, Pollock TM. Scripta Mater 2012;66:574

[32] Tanaka K, Ooshima M, Tsuno N, Sato A, Inui H. Phil Mag 2012;92(32):4011

[33. Pineau A Acta Metal 1976;24:559

[34] Reed RC. The Superallloys: Fundamentals and Applications, Cambridge University Press, Cambridge, 2006. p. 83.

[35] Tian LX, Ma CL. Mater Sci \& Eng A 2015;620:198 